\title{
A TEORIA DO SONHO DE F. S. PERLS: EVOLUÇÃO, PROBLEMAS TEÓRICOS E PRÁTICOS
}

\author{
F. S. Perls's dream theory: evolution, theoretical and practical problems \\ La teoría del sueño de F. S. Perls: evolución, problemas teóricos y prácticos
}

David CEBAlLos

\begin{abstract}
Resumo: A teoria sobre sonhos criada por F. S. Perls tem sido tradicionalmente caracterizada como uma projeção ou uma mensagem existencial. No entanto, esta descrição representa apenas uma explicação simplista da conceituação mais ampla e original do fenômeno onírico desenvolvida por Perls. Este artigo apresenta uma exposição ordenada da teoria perlsiana do sonho e uma análise crítica de seus pressupostos, com especial atenção para os erros inerentes a ela e suas implicações na prática clínica. Conclui-se que a teoria perlsiana dos sonhos evoluiu em três fases a saber, a) modelo original do sonho, b) modelo de correspondência, e c) modelo clássico de sono. Cada um desses modelos constitui-se de forma própria como uma teoria específica sobre sonhos na qual define o fenômeno onírico de uma maneira particular e lhe são atribuídos funções psicológicas e terapêuticas concretas, bem como uma metodologia de trabalho específica. Palavras-clave: Gestalt-terapía, Sonhos, Alucinações, Fantasia, Imagem eidética.
\end{abstract}

\begin{abstract}
The dream theory created by F. S. Perls, traditionally, has been characterized as a projection or an existential message. However, this description only represents a simplistic explanation of the broader and original conceptualization of the dream phenomenon developed by Perls. In this regard, in this paper an orderly exposition of the perlsian theory of the dream is done, as well as a critical analysis of the propositions on which it is based, paying special attention to the errors inherent in it and its implications in clinical practice. It is concluded that the perlsian theory of the oneiric evolved in three stages, namely, original model of the dream, model of correspondence and classical model of the dream, each of which constitutes, in its own right, a theory of the dream in which it defines the dream phenomenon in a particular way and is attributed to specific psychological and therapeutic functions, as well as a specific work methodology.
\end{abstract}

Keywords: Gestalt therapy, Dreams, Hallucinations, Fantasy, Eidetic imagery.

Resumen: La teoría del sueño creada por F. S. Perls, tradicionalmente, ha sido caracterizada como una proyección o un mensaje existencial. Sin embargo, esta descripción sólo representa una explicación simplista de la conceptualización más amplia y original del fenómeno onírico desarrollada por Perls. En este sentido, en el presente escrito se hace una exposición ordenada de la teoría perlsiana del sueño, así como un análisis crítico de las proposiciones en las cuales se fundamenta, prestando especial atención a los errores inherentes en ésta y sus implicaciones en la práctica clínica. Se concluye que la teoría perlsiana de lo onírico evolucionó en tres etapas, a saber, modelo original del sueño, modelo de correspondencia y modelo clásico del sueño, cada uno de los cuales constituye, por derecho propio, una teoría del sueño en la cual se define el fenómeno onírico de una manera particular y se le atribuyen funciones psicológicas y terapéuticas concretas, al igual que una metodología de trabajo específica.

Palabras clave: Terapia gestalt, Sueños, Alucinaciones, Fantasía, Imagen eidética.

\section{Introducción}

En términos generales, la teoría del sueño planteada por Frederick S. Perls ha sido caracterizada, dentro y fuera del ámbito de la terapia gestalt, como una proyección o un mensaje existencial. Sin embargo, esta descripción sólo representa una pequeña fracción dentro de la conceptualización más amplia y original del fenómeno onírico desarrollada a lo largo de toda su carrera profesional. Desafortunadamente, la teoría perlsiana del sueño ha sido incomprendida a tal grado que su exposición se ha visto reducida a una serie de expresiones lacónicas, las cuales denotan un desconocimiento, casi total, de la profundidad de la hipótesis gestalt del sueño, su evolución, así como, los problemas inherentes en sus proposiciones e implicaciones en la práctica de la psicoterapia. Si bien, algunos profesionales de la gestalt han intentado hacer una exposición ordenada de la teoría gestalt del sueño $\mathrm{y}$, en menor medida, de articular una teoría del fenómeno onírico desde el marco conceptual de la terapia gestalt; lamentablemente, estos exhiben una serie de problemas recurrentes en el tratamiento de esta materia, a saber: (a) una aproximación unilateral al fenómeno onírico, ya sea como proyección o retroflexión; (b) desconocimiento de los supuestos subyacentes en la hipótesis perlsiana del sueño; (c) errores en la definición del sueño, esto es, confusión entre características del sueño, funciones psíquicas del sueño, mecanismos de elaboración onírica y, lo que Simkin denominó como, función terapéutica del sueño; y, finalmente, (d) en la medida en que estas cuestiones se circunscriben al estatus ontológico y 
epistemológico del sueño, a una falta de discusión sobre estos asuntos.

Aunque, estas dificultades se pueden atribuir a la forma ambigua en la que Perls abordó estas cuestiones, ya que nunca estableció una demarcación explícita entre cualidades, procesos y funciones del sueño; así como a las inconsistencias teoréticas concurrentes en los distintos modelos del sueño por él postulados, las cuales jamás logró conciliar $\mathrm{y}$ presentar de manera coherente y consistente. Igualmente, cabe señalar que la persistencia de estos problemas también se ha debido al poco interés por parte de los profesionales de la terapia gestalt por desarrollar una teoría del fenómeno onírico desde el corpus teorético de este enfoque. De manera que, hoy por hoy, la terapia gestalt no cuenta de manera plena con una teoría de los sueños.

En vista de las dificultades existentes en la teoría del sueño de la terapia gestalt en el presente ensayo se propone trazar una exposición crítica y sistemática de las hipótesis del sueño esbozadas por Perls, poniendo especial atención a las proposiciones que fundamentan la teoría perlsiana, los problemas expresos en éstas y sus implicaciones en la metodología del trabajo con sueños, a fin de sentar las bases para la reconstrucción de la perspectiva gestalt del sueño.

\section{La Teoría Perlsiana del Sueño}

La contribución de Fritz Perls a la hermenéutica de lo onírico es vasta. Si bien es cierto que sus innovaciones se ubican, en gran medida, en el terreno de la técnica; con todo, su aportación a la teoría del sueño no deja de ser minúscula sino más bien es amplia y compleja, razón por la cual no se puede hablar de una teoría perlsiana sino de teorías o modelos del sueño, los cuales desarrolló durante casi treinta años. Estas teorías son, substancialmente, el resultado de una síntesis de diversas aproximaciones psicológicas sobre el fenómeno onírico dominantes en la primera mitad del Siglo XX, entre las cuales la teoría freudiana y junguiana del sueño representan la mayor influencia en la construcción de la teoría y método gestalt del trabajo con sueños. En este sentido, el posicionamiento perlsiano ante los problemas que rodean al sueño es análogo al que Freud y Jung manifestaron a través de toda su obra. Sin embargo, en la medida que Perls fue integrando nuevas perspectivas teóricas al marco conceptual de su enfoque psicoterapéutico, su noción sobre el fenómeno onírico evolucionó y terminó por distanciarse, cada vez más, del punto de vista psicoanalítico y de la psicología profunda.

En concreto, en el periodo de desarrollo de la teoría perlsiana del sueño, comprendido entre los años de 1942 a 1970, se pueden distinguir tres etapas que, si bien se superponen, cada una se caracteriza por la adopción de una perspectiva particular sobre el fenómeno onírico y del trabajo con sueños. La primera fase corresponde al modelo original del sueño, cuya tesis central fue formulada y sostenida durante los cuarentas. La segunda etapa está representada por el modelo de correspondencia propuesto a principios de la década de los cincuentas. Y, finalmente, se encuentra el modelo clásico del sueño, el cual Perls enseñó desde los años sesentas hasta el final de su vida.

\section{El Modelo Original del Sueño (1942-1948)}

El modelo del sueño esbozado por Perls (1947), en Ego, Hunger \& Aggression, está enmarcado dentro de una teoría de la personalidad que concibe al organismo en una relación de interdependencia con el entorno. Desde esta perspectiva, el organismo requiere del entorno y los objetos para poder completar sus funciones y crecer. En este contexto, toda conducta, o respuesta del organismo describe una relación funcional entre el organismo y su entorno; la cual es configurada, tanto, por las necesidades organísmicas y los objetos en el entorno. Dicho de otra manera, la respuesta del organismo es la inter-acción entre el organismo y el entorno, o mejor, la conducta es la relación entre el organismo $\mathrm{y}$ el entorno.

Siguiendo estas consideraciones, el soñar se constituye como una respuesta del organismo en el entorno que tiene como fin restaurar su equilibrio. Empero, desde que toda respuesta del organismo humano está en función de una realidad constituida a partir de la interacción de las necesidades e intereses y del entorno al cual se responde, el soñar en la medida que acontece cuando el organismo está dormido, prima facie, se vislumbra como algo imposible. Perls propone como solución al problema que encarna el acto del soñar una visión unitaria del organismo, en la cual los diferentes aspectos de la personalidad humana, a saber, mente y cuerpo, son conceptuados como términos que denotan los distintos factores disposicionales que constituyen las funciones del organismo en el campo. Si bien, cada uno de estos conceptos hacen alusión a las manifestaciones específicas del funcionamiento del organismo humano también, es cierto, que éstos constituyen una diferenciación de la conducta del organismo en el entorno con base en un criterio energético.

A este respecto, es necesario mencionar que Perls (1947) entiende que el comportamiento posee connaturalmente una energía que moviliza al organismo en dos direcciones en una matriz espaciotemporal. Ahora bien, esta energía no sólo es un cofactor sustancial en la génesis de la acción del organismo en el entorno, sino que también configura cualitativamente la conducta dependiendo de la cantidad de energía comprometida, esto es, si la respuesta implica un mayor uso de energía ésta se constituye en acción; en contraste, si esta involucra un 
menor uso de energía se instituye como pensamiento. Es a partir de este axioma que Perls define el pensar como "una acción en dosis homeopáticas... [como] un instrumento que ahorra 'tiempo' y energía” (p. 26). Esto quiere decir, que Perls concibe el pensamiento como una acción del organismo, la cual debido a su aspecto económico posibilita el uso de energía de manera más efectiva. Según Perls, esto obedece a que las funciones o procesos mentales del organismo fusionan experiencias sensoriales en objetos, los cuales son etiquetados como símbolospalabra y, luego, son manipulados como si fueran objetos reales. Es necesario mencionar que Perls no limita las funciones mentales únicamente a procesos de índole verbal sino también considera que "el sistema mental superior, el cual incluye muchas funciones comúnmente conocidas como pensamiento... selecciona, rechaza, combina, recuerda experiencias pasadas, en resumen, hace lo que su escuela ha reconocido como la función del sueño. Intenta solucionar situaciones inconclusas [cursivas añadidas] (Perls 1979/2012a, p. 22)

Por consiguiente, Perls entiende que el sueño es una actividad mental, emergente en una situación de relajación en la que la consciencia está alterada, que tiene como función intentar completar las situaciones inacabadas. Decimos en una situación de relajación en la que la consciencia esta alterada porque cuando el organismo se halla dormido los sistemas de orientación y manipulación se encuentran disminuidos y suspendidos, respectivamente; es decir, el sueño es un proceso espontáneo que ocurre en una situación donde si bien hay interacción entre el organismo y el entorno ésta es especialmente de naturaleza conservadora. Por ende, "no existe un entorno presente, el cual de acuerdo a la función figura/fondo pueda llegar a convertirse en realidad" (Perls, 1979/2012a, p. 22) $y$, en consecuencia, se logren satisfacer las necesidades. De lo anterior, se desprende que cuando el organismo está soñando no se establece contacto con el objeto satisfactor, por lo que no se puede hablar de asimilación de los objetos-de-contacto y mucho menos de crecimiento. Sin embargo, Perls (1979/2012a) prosigue en su razonamiento y alega que "visualizamos, fantaseamos, soñamos, o incluso alucinamos arcaicamente la situación requerida para la satisfacción de nuestras necesidades [cursivas añadidas]” (p. 22). En este punto conviene subrayar que Perls es inconsistente en torno a la función del sueño ya que si bien, por un lado, afirma que mediante el sueño se satisfacen las necesidades inconclusas, por otra parte, también refiere que el fenómeno onírico es un intento de solución de situaciones inacabadas. De ahí que los sueños contengan "una gran cantidad de material no asimilado" (Perls, 1947, p. 204), los cuales se buscan asimilar a través del proceso onírico. En este sentido, si el soñar se instaurara, efectivamente, como un proceso de compleción de figuras, esto es, de asimilación, esto tornaría en absurdo cualquier proceso asimilativo ex post facto, ya que el material inasimilado en el contenido de los sueños ya habría sido asimilado a través del proceso del sueño y, por ende, el trabajo terapéutico con las formaciones oníricas resultaría innecesario. Sin embargo, esto no es lo que Perls parece decir sino más bien que el sueño es una satisfacción alucinatoria pero no real, es decir, "indirecta” mas no "directa”. De ahí que Perls (1947) calificara a "los sueños agradables... [como] compleciones directas o indirectas de situaciones incompletas" (p. 240).

Como se puede notar, Perls no es tajante en torno a estas cuestiones, las cuales jamás esclareció, no obstante, al conferirle al sueño una función compensatoria, las inconsistencias antepuestas en parte pueden solventarse ya que la función onírica no se restringe exclusivamente a la satisfacción de las necesidades del organismo insatisfechas en la vigilia; sino que también comprende la eliminación de las tensiones generadas por los estímulos propioceptivos, interoceptivos y exteroceptivos que perturban el dormir (p. ej., la necesidad de micción, sed, temperatura, etc.) a través del drama onírico. Nótese bien, que en la medida que el soñar es una actividad que sucede mientras el organismo está en reposo, este se halla estrechamente relacionado con el dormir, en tal manera, que sin éste el organismo no podría descansar; de ahí que Perls (1947) diga que "el sueño es un compromiso con el dormir y la situación incompleta” (p. 261). En este sentido, la primera función que tiene el sueño es satisfacer la necesidad de dormir, a fin de proporcionar descanso al organismo, desde que "el propósito del dormir: es dar descanso y frescura” (p. 258).

Es a partir de estas nociones que, tradicionalmente, los terapeutas gestalt han concluido que el sueño es una tentativa de autorregulación organísmica o bien un intento insatisfactorio por completar figuras. Si bien estas aserciones son mucho más atinadas, pues no afirman categóricamente que mediante el sueño se satisfagan necesidades inconclusas; empero, son equívocas puesto que definir al sueño como la tentativa de compleción de una situación inacabada es una declaración extensionalmente inexacta porque, evidentemente, existen sueños que no representan esta situación. Con relación a esto, Perls (1947) refiere que hay dos clases de sueños: "los sueños agradables son compleciones directas o indirectas de situaciones incompletas: coinciden con el cumplimiento del deseo de acuerdo con la terminología de Freud. [Y] los sueños desagradables [los cuales] contienen invariablemente proyecciones, su prototipo mejor conocido es la pesadilla (p. 240). Como se puede apreciar, Perls no dice aquí que las pesadillas constituyan una compleción sino más bien una proyección de lo no deseado. Por tanto, 
la conceptualización del sueño como situación inacabada simple y llanamente alude a la función del sueño mas no a su definición, puesto que dicha función sólo se efectúa en tanto que en la trama onírica se compensan alucinatoriamente las necesidades insatisfechas; lo cual, naturalmente, excluye a las pesadillas.

Hasta este punto, Perls no dice nada nuevo sobre la función del sueño, únicamente articula las ideas freudianas y junguianas en términos de la psicología gestalt. Ciertamente, ya Freud había vislumbrado que el sueño implicaba un intento por librar al soñante de las perturbaciones que amenazaban su estado de reposo por medio de la realización de un deseo, de manera que el sueño se instituía como el guardián del dormir. Tesis a partir de la cual Freud infirió que el sueño, entre otras cosas, era una proyección, es decir, una externalización de un proceso interno. Por otro lado, Jung también había señalado que cuando algún proceso no podía ser equilibrado a través de la autorregulación de la psique, este hecho inmediata e inevitablemente provocaba una compensación; observación a partir de la cual calificó la teoría de la compensación como una ley básica de la conducta psíquica, ley que encontraba su mejor prueba en la interpretación de los sueños. En este contexto, la hipótesis perlsiana queda enmarcada, en cierto modo, dentro de las formas posibles que puede tomar la compensación. Es decir, Perls, al igual que Jung, comprende que el sueño desempeña una función compensatoria; empero, para él esta función no se limita estrictamente al plano "psicológico" sino que integra el nivel biológico y social.

Planteamiento ontológico del sueño. Tal como se ha visto, Perls no se separó considerablemente del enfoque psicoanalítico de los sueños, él mismo reconoce que su postura es semejante a la idea freudiana del cumplimiento del deseo. Sin embargo, cuando Freud deduce, con base a las leyes que rigen el funcionamiento del aparato psíquico, que en la medida que el sueño implica la reproducción de las percepciones de las imágenes mnémicas, que éste es una alucinación; Perls terminó por tomar una postura completamente diferente.

A este tenor, se puede señalar que entre los principales factores que terminaron por explicitar la visión perlsiana sobre la naturaleza del sueño se encuentran, en primer lugar, el rechazo de la noción psicoanalítica del inconsciente, la teoría de la represión, la teoría del yo, etcétera. De manera que, al impugnar la metapsicología psicoanalítica, también estaba negando los principios que explicaban la formación del sueño. Consiguientemente, la teoría perlsiana del sueño no supone la existencia de mecanismos de elaboración onírica (p. ej., desplazamiento, condensación, etc.), como efectos de la censura, durante el proceso de formación del sueño; y, por ende, mucho menos la presencia de un mecanismo censor. En este sentido, la singularidad de las imágenes oníricas desde la teoría perlsiana no obedece a la operación de mecanismos de deformación sino a otros factores. Sobre este asunto Perls (1947) dice que el cariz de ininteligibilidad del sueño se debe a que éste contiene "una gran cantidad de material no asimilado" (p. 204); mas no a una tendencia hacia la "expresión simbólica del inconsciente... [en otras palabras, a la consideración a la representabilidad, sino más bien a] una proyección que encubre" (p. 203) los objetos reales con imágenes de otros objetos. De ahí que, más tarde y sobre todo en la década de los sesentas, Perls subrayara que "el soñar es espontáneo e indeliberado" (Perls, Hefferline \& Goodman, 1951, p. 265). Empero, al introducir el mecanismo de proyección en la génesis de las imágenes del sueño, Perls estaba estableciendo, en contra de todo lo que ya había dicho, la presencia de procesos de formación onírica en el sueño. Es así que, Perls (1947) dijo:

La naturaleza proyectiva de las partes del sueño es más fácil de comprender que la mayoría de las otras proyecciones; mientras que en la proyección ordinaria partes del mundo exterior se confunden con lo que en realidad es intraorgánico, en el sueño encontramos un punto-cero: el conocimiento de que un sueño tiene lugar dentro de nuestro organismo, pero que al mismo tiempo tiene la cualidad de tener lugar en el mundo exterior. (pp. 240-241)

Pese a estas discrepancias este supuesto tiene un aspecto importante que se coligue de la naturaleza proyectiva del sueño, a saber, que la proyección que interviene o que se despliega durante el proceso del sueño no es una proyección ordinaria sino una proyección, por usar un término goodmaniano, en voz media ${ }^{1}$, de manera que la cualidad alucinatoria de la proyección ordinaria, desde que "las proyecciones son, en el sentido más estricto, alucinaciones" (Perls, 1947, p. 161), también se encuentra indiferenciada en la proyección sui generis que acontece al soñar. De lo anterior se sigue, que la experiencia onírica no representa tanto una alucinación (como supuso Freud) salvo por su carácter de realidad sino un fenómeno de otro tipo. Ahora bien, si para Perls la experiencia onírica no representa una alucinación cabe preguntarse ¿cuál es la naturaleza del sueño? Ya que "siempre... experimentamos un sueño como una realidad" (Perls, 1979/2012a, p. 28).

Para poder comprender el posicionamiento ontológico perlsiano del sueño es necesario entender

1 Perls (1947) distingue varios tipos de proyección, entre éstos menciona la proyección ordinaria y la proyección intraorgánica. Por proyección ordinaria Perls comprende un proceso de desplazamiento en el cual "algo" del organismo es eyectado hacia el entorno. Por otra parte, la proyección intraorgánica implica un desplazamiento de "algo" en el organismo, por ejemplo, en el cuerpo o en la consciencia; por tanto, este tipo de proyección no debe de entenderse como un proceso meramente intrapsíquico. 
que para él la realidad no es objetiva ni subjetiva sino intersubjetiva y que, si bien acepta la existencia de una realidad subjetiva y otra objetiva, en última instancia, arguye que ambas son interdependientes y que, tanto los intereses y necesidades del organismo, como el mundo objetivo configuran la realidad de acuerdo al principio figura-fondo. Ahora bien, para Perls la relación figura-fondo no se suscribe absolutamente a nivel epistémico, ya que dicho nexo también se aplica a la relación entre el organismo y entorno, así como a "la relación entre cuerpo/alma y mente. [De manera que] la imagen [del objeto satisfactor] en la mente desaparece... tan pronto como se satisface la necesidad del organismo. Exactamente lo mismo sucede con nuestras realidades subjetivas; desaparecen una vez que no se les requiere más” (Perls, 1947, p. 42).

Ahora, dado que en la situación onírica el organismo no tiene contacto con el entorno, por tanto, se sigue que, en el estado del dormir la realidad onírica está formada especialmente de las imágenes de los objetos satisfactores que emergen del fondo del cuerpo relajado. De este modo, el sueño se erige como una realidad subjetiva creada por los intereses y necesidades del organismo representados en forma metafórica en la sucesión de imágenes, sensaciones y sentimientos que caracterizan la experiencia onírica. Ahora, mientras que en el estado de vigilia la fenomenología de la experiencia, el carácter fenomenal de las imágenes, sonidos y sensaciones, es decir, los contenidos de la percepción, son dados en el contacto con los objetos en el entorno a través de los sistemas de orientación y manipulación; en contraste, en el estado de reposo el sistema sensorial y motor se encuentran disminuidos, por tanto, la percepción, en un sentido ordinario, resulta imposible. En este contexto, Perls entiende que el carácter de realidad de los sueños no se explica lo suficiente por las imágenes mentales, las visualizaciones, sino que necesita de ese elemento experiencial que caracteriza a la percepción en la vigilia. Es así que Perls (1947), a fin de conferirle un estatus experiencial al sueño, establece que el sueño representa un estado pre-diferencial en donde la visualización y la percepción son idénticas, a saber, el estado eidético ${ }^{2}$, el cual le concede al sueño su cariz de realidad. A este respecto Perls dice:

Originalmente, las percepciones y visualizaciones no están diferenciadas, sino que son idénticas. Uno puede experimentar esto en los sueños. En un sueño vívido, uno está realmente dentro de la situación, la cual uno experimenta como si fuera una realidad. Cuando se está despierto, muy pocas personas son capaces de recordar y revivir un sueño

\footnotetext{
2 La imaginería eidética es un fenómeno visual subjetivo inusualmente vívido, en el cual una persona afirma que continúa "viendo" un objeto que no está objetivamente presente. En esta situación las personas se comportan y describen el objeto como si estuviera presente y no como si lo estuvieran recordando. En este sentido, este fenómeno no se debe confundir con la memoria eidética o la memoria fotográfica.
}

con toda su intensidad original. Recuerdan únicamente el material, y sólo de vez en cuando pueden producir alguna emoción experimentada durante el sueño. La identidad de la percepción y la visualización en el sueño, su carácter alucinatorio, se manifiesta por la decepción o el alivio experimentado cuando uno se da cuenta del hecho de que el sueño fue "solo un sueño". (p. 42)

Si bien, el posicionamiento ontológico perlsiano representa un acercamiento interesante ante el fenómeno onírico, no deja de ser problemático. Ya que, en la medida en que Perls insistió en calificar al estado eidético como "carácter alucinatorio", la conceptualización del sueño se vuelve difusa, en tal forma, que no se puede ultimar si éste es en pleno derecho imaginería eidética o alucinación. Esta situación se refuerza todavía más al definir a la proyección como una alucinación y, más tarde, al afirmar que "todo sueño es una alucinación" (Perls, 1969b, "Yet I feel real and content.", párr. 5). A esto añádase, que tanto la imaginería eidética y la alucinación son fenómenos que se distinguen completamente entre sí y del sueño, por consiguiente, ni el sueño es una alucinación, ni tampoco la alucinación es imaginería eidética, y viceversa. Una cuestión todavía más importante reside en el hecho el cual incluso Perls puntualizó- de que la imaginería eidética sólo se presenta, usualmente, en algunos niños (en quienes esta característica disminuye con la edad) y en algunos adultos, al igual que, en personas con lesión cerebral. En consecuencia, si la imaginería eidética no es una característica común en todos los miembros de la población, ¿cómo es posible que los miembros restantes puedan ser partícipes de la experiencia onírica? El hecho es que Perls no toma en consideración esta cuestión, por lo que no ve impedimento en fundamentar su metodología del trabajo con sueños en estas suposiciones.

Trabajo con sueños. Como ya se mencionó, dado que en esta época el sueño es visto como una situación inconclusa, en cuanto a su función, es por más evidente que el criterio central para determinar si un sueño es objeto de intervención es si este cumple con su propósito, esto es, en qué grado la trama onírica completa una situación inacabada. Es a causa de esto que Perls (1948) dirá que "la parte más importante del sueño es su final... [ya que] a menudo el sueño trabaja para la solución de un problema” (p. 582). De lo anterior se sigue que no todo sueño es susceptible de trabajo sino sólo aquellos que no resuelven un problema o conflicto, por lo menos, así lo declaran Perls et al (1951) cuando dicen:

La expresión clásica "conflicto interno" contiene... una verdad muy importante... Es que los conflictos internos... las tensiones 
opuestas y las comprobaciones, y los balances del sistema fisiológico, el juego, los sueños [cursivas añadidas], el arte, etc... todos estos son la mayor parte de las veces confiables y no neuróticos; se puede confiar en que son autorregulantes... Los conflictos internos en este sentido no son el tema de la psicoterapia [cursivas añadidas]; cuando son inconscientes, pueden seguir siendo inconscientes. (p. 355)

Por tanto, si los sueños en general son compleciones directas o indirectas de situaciones incompletas, es decir, cumplen con su función autorregulante, en consecuencia, se puede ultimar que los únicos sueños objeto de tratamiento son aquellos en los que no se completa una situación (los sueños desagradables según la clasificación perlsiana), ya sea, porque no solucionan un problema, resuelven un conflicto interno, satisfacen una necesidad o porque el soñante despierta $\mathrm{y}$ no termina el sueño. Dentro de esta categoría, el prototipo por defecto es la pesadilla, debido a que sus contenidos están compuestos de elementos desagradables, los cuales representan una situación emocional inconfortable (miedo, ansiedad, tristeza, etc.), que ocasiona que el soñante se despierte. Es así que, la pesadilla se constituye como paradigma de la situación onírica inconclusa. Esto se pone de manifiesto, cuando Perls (1947) refiere, a lo largo de las páginas de su ópera prima, como ejemplos de la clínica de lo onírico, principalmente, pesadillas. Ya que, según menciona, las pesadillas "contienen invariablemente proyecciones... partes no deseadas" (p. 240) de la personalidad que no se han asimilado.

Es a causa de que, en este periodo, se considera al sueño como una imagen eidética y que su función consiste en completar las situaciones inacabadas, que la meta terapéutica del trabajo con sueños se dirige, precisamente, hacia la compleción y asimilación del sueño. Para lograr estos objetivos, Perls propone como metodología de trabajo la técnica de concentración, o de visualización, de las imágenes que conforman el sueño, la cual, dicho brevemente, radicaba en: (a) prestar atención a cada uno de los ítems que forman el sueño, (b) describir detalladamente cada una de las imágenes oníricas con la intención de asimilar, y (c) llegar a una catarsis emocional mediante la concentración visual. Sin embargo, Perls (1947) no limitó su técnica de concentración exclusivamente a la visualización, sino que prescribió la utilización de los demás sentidos (gusto, olfato, etcétera), pero sobre todo consideró que el sentido del tacto (tocar, moverse) era imprescindible para desarrollar "una sensación apropiada de las cosas e introduc[ir] la experiencia de las cuatro dimensiones... [de desarrollar el] sentido de actualidad y [ayudar] a generar esa memoria eidética [sic] (identidad de percepción y visualización) que en los sueños mismos está siempre presente [cursivas añadidas]” (p. 205).
Nótese que al basarse en el supuesto de que la situación onírica es un estado eidético la técnica del trabajo con sueños se orienta, indefectiblemente, a recrear en la vigilia el mismo estado que se presenta en el sueño, a re-experienciar el sueño emocional, kinestésica y sensorialmente. Si bien, este acercamiento al trabajo con sueños puede parecer nuevo, en realidad, no lo es ya que mucho antes Jung había desarrollado y utilizado la técnica de imaginación activa para trabajar con las imágenes del inconsciente. Aunque, ciertamente, existen algunas diferencias entre ambas técnicas, con todo, la técnica de la concentración visual perlsiana continúa evocando a la técnica junguiana, especialmente, al modo en que la han practicado algunos post-junguianos.

En torno a las críticas hacia la técnica perlsiana de concentración visual se esgrimen los mismos señalamientos relativos a la conceptualización del sueño como una imagen eidética, esto es, cómo se pretende recrear, mediante esta técnica, una imagen eidética si existen factores constitucionales que limitan su aplicabilidad a todos los individuos. En lo tocante a los criterios que estipulan cuáles sueños son objeto de trabajo, Perls es laxo con relación a los principios que definen qué sueño debe ser trabajado o no. A pesar de que él propuso una clasificación de sueños en dos categorías (agradables y desagradables), basada en la ley de cierre de una figura, con todo, dicha norma es bastante amplia como para concluir, más allá de la interrupción del sueño o de las pesadillas, que sueño cumple o no con su función. Este es un problema al cual él mismo se enfrentó y, que como se verá después, resolvió de manera equivocada.

\section{El Modelo de Correspondencia (1950-1960)}

Hacia principios de la década de los cincuentas Perls tenía residiendo en Norteamérica cerca de cuatro años, lapso de tiempo durante el cual tuvo contacto con nuevas ideas, entre las cuales la técnica de Moreno para el trabajo con sueños, las ideas de Sullivan, Rank y Goodman concernientes al fenómeno onírico, representaron la principal influencia sobre su teoría de los sueños. ${ }^{3}$ Durante estos años Perls no modificó substancialmente su perspectiva sobre los sueños, según se puede observar en los pocos escritos y conferencias publicadas de manera póstuma, por lo que no es posible afirmar, categóricamente, cuál es el estado final de su teoría y técnica en aquel tiempo. No obstante, a partir de los textos existentes se puede deducir que en esta época la teoría perlsiana del sueño alcanza su punto más álgido, ya que los postulados en los que ésta se apoya son planteados y explicados con mayor claridad; y porque muchos de los planteamientos que Perls hizo a la postre no significaron tanto un avance 3 En esta sección no se aborda el enfoque de los sueños planteado en Perls et al (1951). Una exposición más detallada sobre este tema se puede leer en Ceballos (2016). 
-salvo unas excepciones- sino, por el contrario, una repetición simplista e incluso opuesta a su formulación temprana. En este sentido, esta fase constituye una etapa intermedia en la que varias tesis sobre el sueño, por un lado, mantuvieron cierta proximidad con el modelo original del sueño y, otras, se acercaron más al modelo clásico. Entre éstas la más importante es la que se refiere al nexo entre creación y proyección, sin embargo, una exposición de este tópico rebasa los límites de este ensayo; otra cuestión señalada por Perls, en este periodo, y que guarda una relación estrecha con la noción de creación es la tesis que define al sueño como una paradoja, desde la cual la función del sueño consiste en solucionar las paradojas irresueltas de la vida diaria del soñante las cuales subsistían en la situación onírica. Sin embargo, por más que Perls estableció una correlación entre los acontecimientos de la vigilia y los sucesos representados en el sueño, él no concluyó que lo onírico fuera una continuidad de la vida o un modo de existencia como lo hicieran los fenomenólogos y existencialistas sino más bien una correspondencia biunívoca. Lo que da pie a revisar una de las contribuciones más importantes de Perls a la teoría del sueño de la terapia gestalt, a la cual, desdichadamente, no se le ha prestado la atención debida.

Correspondencia entre Realidad y Fantasía. De nuevo, en estos años Perls (1976, 1978/2012b) retoma la tesis según la cual la actividad mental y las funciones de la mente son conductas de bajo nivel de energía del organismo en su totalidad, resultantes de la cualidad de la interacción en el entorno. Según Perls la conducta del organismo se conforma de acuerdo a las condiciones del entorno, si la situación es de alta intensidad "el organismo actúa con y reacciona a su entorno con mayor o menor intensidad; a medida que la intensidad disminuye, el comportamiento físico se convierte en comportamiento mental. $\mathrm{Y}$ a medida que la intensidad aumenta, el comportamiento mental se convierte en comportamiento físico" (Perls, 1976, p. 14). En este contexto, dado que en el estado del dormir la situación no requiere de una respuesta de alta intensidad la actividad física puede considerarse de bajo orden, sin embargo, dice Perls "requiere un uso considerable de nuestras capacidades fisiológicas integradas. [Y aunque] los músculos no están tan activos durante el dormir como en el estado de vigilia; no obstante, existe inevitablemente cierto grado de actividad" (p. 11). Esta actividad que se despliega durante el dormir es, por razones obvias, el soñar.

De acuerdo con Perls (1976), la conducta mental o "el pensamiento incluye una serie de actividades -soñar, imaginar, teorizar, anticipar- haciendo un máximo uso de nuestra capacidad para manipular símbolos” (p. 12). Por tanto, Perls (1978/2012b) entiende que el soñar es una conducta mental, o mejor dicho una respuesta de bajo nivel del organismo en una situación de baja intensidad. Es decir, el sueño es un fenómeno de campo, es una conducta emergente en una situación donde la interacción entre organismo y entorno es de baja intensidad. $\mathrm{O}$ también una actividad fantasiosa, desde que Perls prefiere llamar al pensamiento: fantasía. De ahí que señale que, aunque: "tenemos la tendencia a unir la noción de racional con el pensar y de irracional con el soñar, sin embargo, las dos actividades son muy parecidas" (Perls 1976, p. 12). Dicha similitud se halla, además de ser actividades de baja intensidad, en que estas funciones implican el uso de símbolos. Esto es, son actividades simbólicas que envuelven la manipulación de signos (p. ej., símbolos, números, palabras), que tienen la peculiaridad de "reproducir la realidad en una escala disminuida" (Perls 1976, p. 12). Los cuales a pesar de que no representan una copia idéntica del mundo real, no obstante "comienzan en la realidad... [y] de alguna manera, siempre están relacionados con la realidad, la cual tiene una existencia significativa para la persona en cuya actividad de fantasía entran” (pp. 12-13). O sea, que por más que el símbolo se constituya en un signo muy diferente de su referente, éste y su significado siempre se encuentran conectados con la situación que representan. Por tanto, el significado y el símbolo se organizan en una relación figurafondo, de manera que no se puede llegar a la toma de consciencia del significado del símbolo si no se considera el contexto desde el cual se originó y forma parte. Consecuentemente, la hermenéutica de lo onírico, en tanto que el sueño es una actividad fantasiosa en función de o como respuesta hacia el entorno, implica un proceso de análisis de la estructura de las relaciones entre símbolo y referente, de búsqueda de relaciones de correspondencia entre fantasía y realidad para descubrir, el significado, la función que cumple el sueño, en tanto que respuesta en el campo. Dicho de otra forma, el trabajo con sueños se fundamenta en el análisis de la unidad de la experiencia onírica considerando que la formación del sueño-figura emerge como una conducta del organismo en el campo organismoentorno. Si bien la correspondencia entre el símbolo y su referente no es absoluta, es lo suficientemente cercana, parafraseando a Perls, como para basar las interpretaciones de los símbolos en la unidad dinámica del campo. Lo anterior, no sólo tiene implicaciones en la metodología del trabajo con sueños sino también en la ontología del fenómeno onírico.

La naturaleza del sueño. En este periodo, el posicionamiento perlsiano en torno a la ontología del sueño presenta una serie de dificultades no sólo con relación a los planteamientos previos, sino también con su proyecto en curso. Ya que al alegar que el soñar es una conducta mental, es decir, una actividad fantasiosa, esto implicaba que el sueño se instauraba ya no como imaginería eidética sino 
estrictamente como un proceso imaginario. Es así que Perls (1978/2012b) dice: "Es cierto que aquí hay una dificultad. La connotación de fantasía es la de algo imaginario, irreal, de no ser una copia verdadera o idéntica del mundo real [cursivas añadidas]” (p. 91). En este sentido, el sueño, en tanto actividad fantasiosa, se manifiesta como una forma de experiencia imaginativa y, como tal, se distingue de la percepción en la situación de vigilia, en que no involucra perceptos y tampoco la sensación de estar presente en el mundo sino más bien una sensación de inmersión cognitiva o ficcional como la experienciada en las ensoñaciones diurnas. El mismo Perls, al hablar sobre las diferencias entre percepción e imaginación, señala mediante un ejemplo que cuando:

Veo un árbol. Para ello necesito el ojo y el cerebro registrador. Tengo que dirigir mi atención o prestar atención al árbol; luego me doy cuenta de algo que puedo reconocer $\mathrm{y}$, si lo deseo, lo etiqueto como “árbol”. Bloqueo el entorno, cierro los ojos... Visualizo un árbol. Fácilmente podríamos decir que me imagino un árbol. Esto puede, pero también podría no ser una réplica exacta del árbol anterior; en cualquier caso, esta es una realidad, pero no una realidad física, de la que soy consciente [aware]. Me imagino "mirando" a un árbol. Esto es importante porque no es el árbol lo que es relevante en este caso, sino la actividad fantaseada de mirar. (Perls 1978/2012b, p. 91)

Es decir, que la imaginación o actividad fantaseada no es la realidad sino una sustitución de la realidad pues evidentemente no se realiza la acción, sino que se imagina que ésta se lleva cabo. En torno a estos señalamientos Perls (1978/2012b) escribe que "el propósito de estas actividades fantasiosas es proporcionar un sustituto de las actividades físicas que representan... [cursivas añadidas]. El objetivo de fantasear, especialmente del fantasear racional es, en efecto, restringir nuestras actividades físicas hasta el punto en que aparezcan como acciones homeopáticas o diminutas” (p. 92). Ciertamente, se puede objetar que lo anterior atañe únicamente al caso de las fantasías en el estado de vigilia; sin embargo, ello no se circunscribe exclusivamente a la vigilia sino también al estado del dormir, en el cual la actividad fantasiosa del soñar ocurre. De esto da cuenta Perls al decir que "el origen de la fantasía radica en la frustración. Si hay satisfacción, la Gestalt se cierra y no queda ninguna excitación que continúe el evento en cuestión. El ensueño y, frecuentemente, el sueño, que son satisfacciones sustitutivas [ersatz] y negaciones de frustraciones, lo confirman” (p. 95). En consecuencia, el sueño viene a ser una formación sustitutiva, en su acepción psicoanalítica, una formación imaginaria, mediante la cual el organismo intenta restablecer el balance organísmico que no se pudo conseguir en el estado de vigilia.

A pesar de la relevancia teórica de estas disquisiciones alrededor del estatus ontológico del sueño, estas conclusiones no son decisivas sino más bien ambiguas ya que Perls (1976), por un lado, incluyó a la imaginación como una de las actividades que comprendían el pensamiento o fantasía; y por otro, también concibió que fantasía e imaginación eran actividades homólogas (Perls 1978/2012b). Es decir, no hay una claridad conceptual sobre la noción de fantasía. De cualquier manera, como ya se sugirió, al definir al sueño como imaginación esta perspectiva se oponía por completo a la postura original en la cual el sueño gravitaba en un punto intermedio entre percepción y visualización. Empero, la tesis de que el sueño es una experiencia imaginativa no fue trasladada a la práctica del trabajo con sueños, puesto que Perls terminó por considerar al sueño como una proyección y, en consecuencia, el trabajo con sueños como un asunto de re-identificación o integración.

\section{El Modelo Clásico del Sueño (1960-1970)}

La hipótesis de los sueños enseñada durante la década de los años sesenta ha llegado a ser el referente por excelencia de la teoría gestalt del sueño. De modo que, cuando se habla de sueños, por antonomasia, se está hablando de proyección y, por ende, de un mensaje existencial. Sin embargo, como se pretende demostrar esta afirmación no es del todo cierta. Tal como se ha señalado la tesis que postula que el sueño es una proyección no es nueva, ya Perls había estado trabajando con este supuesto desde antaño, sin embargo, un análisis minucioso muestra que el tratamiento que le confirió ulteriormente conllevó un cambio radical en su teoría de lo onírico, aun cuando continuó utilizando dicho término. Para comprender mejor este cambio de perspectiva es preciso examinar las premisas en que se fundamenta la teoría clásica del sueño (Perls, 1966, 1969a, 1969b). Ordinariamente, se ha definido al sueño como una proyección, sin embargo, esta proposición sólo representa una premisa dentro del argumento perlsiano del sueño, el cual puede presentarse de la siguiente manera:

1. Los sueños son proyecciones (Perls, 1966).

2. Las proyecciones son alucinaciones (Perls, 1947).

3. Por lo tanto, los sueños son alucinaciones (Perls, 1969b).

Enunciado de esta manera, el argumento del sueño no concluye que el fenómeno onírico sea una proyección, sino que, en contra de todo lo que se pueda alegar, lo que realmente está postulando es 
que "todo sueño es una alucinación” (Perls, 1969b, "Yet I feel real and content", párr. 5). Entre las razones para afirmar esto se tiene que el consecuente (3) le confiere al sueño de un estatus de realidad, es decir, de experiencia fenoménica. Y, por otro lado, también le otorga a la hipótesis perlsiana de cierto nivel de explicatoriedad sobre la naturaleza de las imágenes, sonidos, sensaciones, etcétera, presentes en el sueño. En contraste, la premisa dos simplemente afirma que la proyección es un mecanismo que participa, en cierta medida, de un factor alucinatorio, o bien que es una de las formas posibles en que la alucinación se articula, pero no afirma que la proyección sea per se la alucinación (véase la definición de proyección de Perls 1947 y de Perls et al, 1951); lo que ratifica el consecuente (3). Entonces, ¿qué es lo que ha de entenderse cuando Perls (1966) dice que "el sueño es una proyección" (p. 517)? Siguiendo estos razonamientos, se puede ultimar que lo que la premisa uno está afirmando es que en el proceso de formación onírica participan mecanismos alucinatorios que le confieren al sueño la cualidad de realidad. Es decir, lo que el argumento perlsiano del sueño, y cada una de las premisas que lo integran, está declarando es cuál es la naturaleza del sueño y cuáles son los mecanismos que intervienen en la producción onírica. Sin embargo, este argumento, aunque es válido, no puede ser calificado como sólido a causa de que sus premisas denotan una serie de problemas lógicos, los cuales a continuación serán discutidos.

El sueño como alucinación. El posicionamiento asumido por Perls (1947, 1967, 1968, 1969b) ante el problema ontológico del sueño, en ese entonces, fue similar al adoptado por Freud y Jung, a saber, que el sueño es una experiencia alucinatoria análoga a la que acontece en la psicosis, la paranoia y los delirios. Es decir, es una visión clínica o psicopatológica del sueño, en la que el fenómeno onírico es un síntoma de las perturbaciones del organismo, o en términos de Perls (1969a) un claro indicador de los problemas de la existencia. "Un sueño es un mensaje existencial de las partes de tu personalidad que están perdidas" (Perls 1969a, p. 120), esto es, de las partes alienadas o proyectadas.

Continuando, en la historia de la filosofía y de la medicina la hipótesis de que el sueño es una alucinación ha sido una de las tantas perspectivas desde las cuales se ha intentado abordar el fenómeno onírico. En el terreno de la psiquiatría esta suposición fue común desde finales del siglo XIX y principios del siglo XX. Siendo así, es comprensible porque Freud, Jung y Perls, en tanto que psicoanalistas, hallan defendido esta proposición. Como se recordará, Perls desde un inicio sostuvo esta idea, aunque de manera parcial, la cual le permitía dar cuenta del porqué la percepción de imágenes, sonidos y sensaciones corporales presentes en el sueño se vivenciaban como una realidad. En este punto, es patente que la experiencia del sueño no sólo entraña un problema ontológico sino también epistemológico, ya que la cuestión es ¿cómo es posible la experiencia perceptual en ausencia de estímulos, dado que la alucinación es una experiencia perceptual en ausencia de estímulos del entorno? Perls (1960a, 1969b) es silente ante esta contrariedad, de manera que únicamente se limitó a decir que la razón por la cual el sueño tiene la cualidad de ser absolutamente real es porque es una alucinación.

Si bien, Perls es claro al definir al sueño como una alucinación, no obstante, lo mejor sería decir que el soñar es un proceso que participa de la alucinación, así como de mecanismos que implican el despliegue de la alucinación, a saber, la proyección. No obstante, dada la relación estrecha que Perls observó entre alucinación y proyección sería mejor hablar del binomio alucinaciónproyección, fenómeno que Perls (1947) denominó como alucinación proyectiva. En este sentido, es lógico porque Perls equiparó la experiencia onírica con otros fenómenos que involucraban a la alucinación, como la psicosis (Perls, 1947, 1968), la paranoia o el delirio (Perls, 1970, 1976); ya que todas se supeditaban y se constituían como formas de alucinación proyectiva. En este contexto, se puede advertir porqué el sueño se vivencia como si fuera una experiencia consciente, con una apariencia de realidad, y con el carácter fenomenal de la percepción en la vigilia, ya que involucraba los mismos mecanismos que hacían posible, en sus primeras etapas, el proceso de ajustamiento creativo que se despliega en el estado de consciencia, a saber, proyección y, por ende, alucinación. De ahí que Perls et al (1951) dijeran que la proyección "en el ajuste creativo ordinario, es el factor de alucinación necesario en los primeros acercamientos" (p. 454).

Desgraciadamente, la adopción de esta postura comprometía, implícitamente, la defensa de un escepticismo cartesiano. En el cual Perls incurrió pues al suponer que la proyección y, por defecto, la alucinación, se desplegaban intrínsecamente en el proceso de sensopercepción se estaba admitiendo la posibilidad de que todas las experiencias sensoriales fueran falsas -ya que, en última instancia, estamos proyectando, alucinando. Es así que Perls (1969a) afirma que "todo lo que creamos, veamos en otra persona o en el mundo no es más que una proyección. Podría ser una aberración decir esto, pero es... increíble cuánto proyectamos, y cuán ciegos y sordos estamos a lo que realmente está sucediendo” (p. 57). Y, en consecuencia, a aseverar, como Calderón de la Barca, que la vida es sueño: "la tarea de todas las religiones profundas, especialmente el Budismo Zen, o de una terapia realmente buena, es el satori, el gran despertar, el volver a nuestros sentidos, el despertar de nuestros sueños” (Perls, 1969a, p. 147).

Si bien, la presunción de que el sueño es una alucinación es una idea común en la literatura 
psicológica. Con todo en esta premisa subyacen problemas lógicos que llevan a concluir que el fenómeno onírico en verdad no es una alucinación. La primera de estas dificultades radica en que por definición la alucinación ocurre en un estado de vigilia, sin embargo, el sueño no acontece en la vigilia sino en el estado del dormir e incluso para algunos constituye un estado completamente diferente a la vigilia y el dormir. Incluso tomando en consideración la definición perlsiana de la alucinación, según la cual "las alucinaciones son actividades aditivas, que cubren y, por tanto, evitan la percepción de la realidad" (Perls 1947, p. 67), esta dificultad no alcanza a resolverse. Ya que, en principio, se sigue que dicho mecanismo de evitación se despliega durante el proceso de formación figurafondo, el cual por obvias razones acontece en el estado de vigilia. En este sentido cabe preguntarse qué utilidad tendría la alucinación si el organismo estando dormido ya no percibe su entorno ni las situaciones amenazantes en este; y también cómo es posible el despliegue de la alucinación durante el sueño si no hay percepción de la realidad. Y aunque existen experiencias perceptuales relacionadas con el dormir estas se distinguen del sueño en que acontecen primordialmente en umbrales entre el estado de vigilia y del dormir, y en etapas del dormir que no implican el soñar. Del mismo modo, si bien existen similitudes fenomenológicas entre las alucinaciones y los sueños también se ha de señalar que hay diferencias importantes, p. ej., en los sueños el soñador es un participante directo más que un espectador, mientras que en las alucinaciones se es un observador; por otro lado, las alucinaciones se experimentan como percepciones extrañas o no pertenecientes a uno mismo, en cambio los sueños se viven como propios; igualmente, en las alucinaciones las percepciones están superpuestas a las percepciones verídicas, en contraste, en el sueño no ocurre así; de igual modo, en el sueño no hay un cambio del sentido de sí mismo, de la narrativa personal y las creencias, lo cual si ocurre en las alucinaciones; finalmente, los sueños a menudo, pero no de manera invariable, se olvidan cuando la persona despierta, lo cual difiere prominentemente en el caso de las alucinaciones, las cuales habitualmente se recuerdan bien.

Sueños y producción onírica. A lo largo de estas páginas se ha venido señalando cómo Perls al destacar la naturaleza proyectiva del fenómeno onírico introdujo la noción de mecanismos o procesos de producción onírica en su modelo del sueño. Sin embargo, esta tesis ha sido inadvertida entre los profesionales de la terapia gestalt debido a que ésta ha sido considerada dentro de los enfoques humanistas-existenciales $\mathrm{y}$, al igual que estos, no postula la existencia de un contenido latente del sueño pues comprende que el significado del mismo está dado, en parte, en forma simbólica en el contenido manifiesto del mismo. Por consiguiente, se ha considerado que su marco teórico prescinde de una conceptualización sobre los procesos de formación del sueño, motivo por el cual las hipótesis concernientes al fenómeno onírico en la terapia gestalt, en general, no se han articulado como explicaciones relativas a mecanismos de elaboración onírica -toda vez que tales conclusiones se derivan de las mismas- sino meramente como descripciones cualitativas del sueño. Bajo estas consideraciones, no es de extrañar porque este no ha sido un tópico discutido en la literatura gestalt-salvo en rarísimas ocasiones.

Sin embargo, esta postura contrasta con la tesis perlsiana, ya que suscribir que "el sueño es una proyección” (Perls, 1966, p. 517), por más que se le quiera dar a esta premisa una mera connotación descriptiva, no es más que una petición de principio pues al afirmar esto, por un lado, se está alegando que los elementos de los que se compone el sueño, en tanto que proyecciones, devienen en éste por la acción de la proyección. Pues de qué otra manera se podría explicar el origen de las partes proyectadas de la personalidad en el contenido del sueño sino por la mediación del mecanismo de proyección. Y, por otro lado, que el sueño en sí mismo se asienta como un proceso de proyección. Ahora, para poder comprender como funciona este mecanismo $\mathrm{y}$, por ende, como se forman las figuras oníricas es preciso hacer una serie de elucidaciones, las cuales comúnmente no se toman en cuenta cuando se habla del sueño en terapia gestalt. En primer lugar, conviene subrayar que Perls (1947) concibe la existencia de un dispositivo en el organismo que opera de manera similar a un proyector cinematográfico y que interviene en la producción de las proyecciones. Así, en sentido figurado Perls sugiere que, de la misma forma que en un proyector las imágenes que aparecen en la pantalla provienen de una cinta de celuloide, en el individuo "la mayor parte del material no deseado [de la personalidad] se proyecta en [la pantalla de] el mundo exterior" (p. 159). $Y$ al igual que en un cinema el espectador no es consciente del celuloide, sino únicamente de las imágenes proyectadas en la pantalla, el organismo cuando proyecta no ve o no es consciente de estas partes no deseadas. Por tanto, "la proyección es esencialmente un fenómeno inconsciente" (p. 157). Vista así, la proyección funciona como un proceso que tiene como peculiaridad sustraer aspectos no deseados de la personalidad y agregarlos en el entorno, evitando de esta forma la toma de conciencia de estos. En la terminología arcaica de Perls es un medio de evitación. De ahí que Perls (1969a), al hablar de los sueños hiciera alusión directa a la relación entre el sueño, la proyección y la evitación, como cuando dijo que "todas las partes diferentes del sueño son fragmentos de nuestras personalidades... [son] partes proyectadas y fragmentadas... debido a 
la actitud fóbica, la evitación de la consciencia, gran parte del material que es nuestro... ha sido disociado, alienado, repudiado, expulsado" (p. 67). Por tanto, la proyección se sitúa como el principal mecanismo en la producción de las formas oníricas en la teoría gestalt del sueño. Ya que es a través de la proyección que el material del que se forma el sueño (las partes alienadas de la personalidad) es colocado en éste, pero también es por medio de la proyección que la personalidad es fragmentada. Es decir, la fuente principal del sueño es la personalidad. (Recuérdese que para Perls (1947) la proyección desempeña simultáneamente una función substractiva y aditiva).

El inconveniente con todo esto es que el funcionamiento de la proyección, y las inflexiones que ésta puede tomar, es ilustrada en la situación de vigilia, en donde su objetivo es evitar o interrumpir el contacto. De ahí que la proyección haya sido catalogada como un mecanismo de evitación o una actitud fóbica, ya que por medio de esta se evita, valga la redundancia, la toma de consciencia. Pero cuando el organismo se encuentra en el estado del dormir este no tiene contacto con el entorno y mucho menos es consciente [aware] de éste, entonces ¿cómo es posible el funcionamiento de la proyección mientras se duerme? O isobre qué se proyectan las imágenes oníricas ya que durante el sueño no hay un entorno disponible? Nuevamente, Perls en este punto no da explicación alguna, motivo por el cual simplemente se pueden hacer inferencias sobre las posibles respuestas a estas interrogantes. En este sentido, la primera cuestión puede ser respondida asumiendo que la proyección es un proceso cognitivo que sigue funcionando mientras se duerme, como se recordará, Perls ya había señalado que el soñar es una actividad mental, un tipo de pensamiento, por lo que desde esta perspectiva el sueño consistiría en un tipo de ilusión cognitiva o acaso una creencia. Así lo señala Perls (1967) al decir:

Pensar no es más que hablar en fantasía, un juego de ficción verbal y juegos de combinación. Hay una excepción, creo que podría definir el arte, el verdadero arte es la integración de maya y realidad, es una ilusión y al mismo tiempo es real. Y, por otro lado, la ilusión puede ser tan fuerte que toma el carácter de realidad. Realmente creemos que esta imagen es verdadera como en la fata morgana o en los sueños. Cuando sueñas el sueño más absurdo parece ser real. No hay ninguna duda de que los sueños se experimentan muy vívidamente. (2:12-3:16)

Esto es mucho más patente cuando Perls (1969a) definió el término maya como una actividad mental: "Maya significa algo como una ilusión, o fantasía... Maya es una especie de sueño, un tipo de trance. Muy a menudo... es llamada la mente" (pp. 46-47).

Sólo bajo estas circunstancias sería comprensible porqué la proyección se mantendría en función durante el estado del dormir y porque causa las imágenes oníricas sobrevendrían en el sueño, pues el soñar en tanto que proyección consistiría en una forma de actividad cognitiva en la que no interviene del todo la percepción. Sin embargo, una dificultad inherente en esta premisa es que conduce tácitamente a una posición dualista, la cual, si bien ya se vislumbraba cuando Perls describió el soñar como una actividad mental, en este momento, se hizo más explícita ya que lo que antes era una correspondencia entre el pensar y la realidad se convirtió en dos niveles de existencia: "vivimos en dos niveles: el nivel público que es nuestro hacer, el cual es observable, verificable; y el escenario privado, el escenario del pensar, el escenario del ensayo, en el que nos preparamos para los futuros roles que queremos desempeñar" (Perls 1969a, p. 47). Así, Perls implantaba el dualismo cartesiano y, sin miramientos, hablaba de una teoría de los lugares al hacer referencia a zonas, e introduciendo conceptos tales como zona exterior, zona interior, etcétera (Perls, 1969a); o también mundo interno y mundo externo, o mundo interno de los sueños (Perls, 1979/2012a). De esta forma el teatro cartesiano en Perls devino en un escenario perlsiano en el cual se proyectan los sueños. Con relación a la segunda pregunta tampoco Perls esclarece dónde se proyectan los sueños, es decir, qué cumple la función de pantalla mientras se duerme. A lo sumo, se puede especular cautamente que ésta ocurre en el organismo dado que "no siempre el mundo exterior sirve como pantalla para las proyecciones; también pueden tener lugar dentro de la personalidad (Perls, 1947, p. 158-159). Este es el caso mientras se duerme. De ahí que Perls hable de proyección intraorgánica, pero con todo no se puede concluir dónde tiene lugar la proyección, si es que cabe hacer tal pregunta.

Es evidente, que esta discusión necesariamente lleva a pensar que, para el último Perls, el sueño es un fenómeno intrapsíquico. Basta con comparar este modelo con los anteriores para comprobar que esto es así: en el modelo original y sobre todo en el de correspondencia el fenómeno onírico es una conducta emergente en el campo organismo/entorno, es decir, las fuentes y el material que conforman el sueño provienen tanto de las interacciones tenidas con los objetos y personas en la vigilia, así como de las interacciones que estimulan al organismo mientras está durmiendo (la situación de relajación). A esto se debe que en el contenido del sueño tienen cabida, tanto, conflictos internos y externos; $\mathrm{y}$, por consiguiente, su elucidación admite una combinación de interpretación objetiva y subjetiva. En contraste, en el modelo clásico la única fuente de la que procede el material onírico es intrapsíquica, 
esto es, la personalidad. Y aunque Perls (1976) acepta que en el sueño se representan otras personas termina diciendo que "cada parte del sueño, cada persona, cada cosa, cada estado de ánimo es una parte de nuestro sí mismo [self] fraccionado" (p. 181). Así, todo sueño es interpretado a fortiori como una proyección de la personalidad, como huecos en la personalidad o como un conflicto intrapsíquico.

Si bien, el supuesto del sueño-proyección se contraponía a las declaraciones perlsianas sobre las características del sueño (espontaneidad, creatividad, cualidad artística, etcétera) ello no imposibilitó que Perls continuara postulando a ultranza esta idea y que después, también, otros propusieran más mecanismos de formación onírica, como la retroflexión, la introyección, etcétera, y, en consecuencia, se redujera el fenómeno onírico a sendas categorías, adjudicándole cada vez más una connotación patológica.

Crítica al trabajo con sueños. El trabajo con sueños demostrado por Perls en los sesentas ha venido a ser un punto de referencia no sólo en el terreno de las aproximaciones psicoterapéuticas al fenómeno onírico sino también una seña personal de la terapia gestalt. No obstante, la metodología del trabajo con sueños $\mathrm{y}$, por consiguiente, su fundamentación teórica, no está exenta de críticas. Son varios los terapeutas que han señalado las limitaciones que existen al considerar al sueño como una proyección y sus repercusiones sobre la práctica terapéutica. Principalmente, se ha alegado que dicha metodología: (a) ignora el contacto entre paciente y terapeuta, (b) restringe la forma en que el soñante se identifica con los distintos elementos del sueño, (c) confina la técnica de trabajo a una modalidad individual, (d) delimita el significado del sueño a un evento intrapsíquico, (e) inclusive que dificulta el trabajo con los sueños recurrentes.

Esta situación ha conducido a algunos practicantes de la gestalt a formular no sólo nuevas hipótesis sobre el sueño, aunque esto en menor medida, sino también a crear $y$, especialmente, a importar otras modalidades de trabajo con sueños. Con todo, la mayoría de éstas innovaciones realmente sólo representan una adenda a la teoría y la técnica clásica del sueño, en la medida que tales planteamientos no se han esgrimido como revisiones o desacuerdos con la tesis del sueño como proyección. En virtud de lo cual todavía se continúa formulando como meta terapéutica del trabajo con sueños la integración o asimilación. Sin embargo, la función terapéutica que se le otorga al trabajo con sueños resulta al fin de cuentas inconsistente ya que no se basa en el conjunto total de casos que componen el universo de lo onírico sino en una generalización apresurada en la que se ultima que los sueños categorialmente son vistos como un fenómeno patológico. Si bien algunos terapeutas han reconocido que la concepción de los sueños en la terapia gestalt es negativa, ya que se los cataloga como una proyección patológica o bien como partes perdidas de la personalidad, no obstante, también subrayan que estos son considerados positivamente, como una proyección creativa o una afirmación de quien se es. No obstante, conviene subrayar que estos argumentos se trazan desde la situación terapéutica del trabajo con sueños, es decir, desde el objetivo o resultado que se pretende alcanzar a través de la proyección creativa (estrictamente hablando esto es una asimilación de proyecciones), esto es, que el soñante se reapropie de las partes alienadas de su personalidad. En este escenario, es natural que se valore a la proyección de manera positiva. Pero como se ha venido diciendo esta es una conclusión equivocada pues obnubila entre la función terapéutica del trabajo con sueños y la función psicológica del sueño y, a la vez, confunde y extrapola las cualidades de la así llamada proyección creativa empleada en el trabajo con sueños con la proyección que acontece mientras se sueña.

Este error en la definición del sueño y, por tanto, en el planteamiento del trabajo con sueños se debe no sólo a los equívocos de los teóricos de la gestalt sino también a las inexactitudes en la delimitación del fenómeno de la proyección concurrentes en la teoría original del sueño. Como se recordará desde un inicio Perls señaló que donde mejor se puede apreciar el fenómeno de la proyección es en el mundo de los sueños. Según Perls (1947) hay dos clases de sueños: agradables y desagradables. Los sueños agradables coinciden con la noción freudiana del cumplimiento del deseo son, pues, "deseos proyectados" (p. 240); por otro lado, los sueños desagradables corresponden a las pesadillas, estas "contienen invariablemente proyecciones... partes no deseadas [de la personalidad]" (p. 240). A partir de lo anterior, se puede advertir que el contenido de los sueños está formado, de manera invariable, por proyecciones, ya sea de aspectos deseados o indeseados -Perls (1970) también refirió que "algunas de las piezas [que forman el sueño] provienen de la memoria o la realidad" (p. 27). Pero, el inconveniente con esta clasificación es que se centra exclusivamente en el contenido del sueño mas no en los mecanismos subyacentes a estos, de tal manera, que se da por sentado que la formación de cada clase de sueño se debe a la operación de un tipo único de proyección cuando en la teoría perlsiana figuran varias especies de proyección, consecuentemente, esto le llevó, tanto, a él como a sus seguidores a identificar y a tratar todos los sueños como pertenecientes a una misma clase y a una misma especie de proyección. Como es sabido, hacia finales de los sesentas Perls (1969a) distinguió entre proyección parcial (la cual es patológica) y proyección total (la cual es sinónimo de la experiencia artística y de la identificación); división a partir de 
la cual, usualmente, se ha asumido que el sueño es el resultado de la proyección total, aunque es cierto que Perls mencionó que el sueño es una obra de arte, de esto no se desprende que el sueño sea producto de la proyección total. Entre las razones para afirmar esto se tiene, en primer lugar, que, si el sueño fuera producto de la proyección total, el trabajo con sueños en primera instancia resultaría innecesario pues, de cierto, se estaría repitiendo un proceso ya realizado durante el acto de soñar; en segundo lugar, Perls (1969a) jamás aseveró que el sueño fuera una proyección total sino todo lo contrario, es decir, una proyección parcial, motivo por el cual propuso como solución la proyección total. Así lo deja de manifiesto al decir que: "Podemos reasimilar, podemos recuperar nuestras proyecciones [parciales], proyectándonos completamente en esa otra cosa o persona. Lo patológico es siempre la proyección-parcial. La proyección total es llamada experiencia artística, y esta proyección total es una identificación con la cosa en cuestión” (p. 67).Es decir, el hecho de que el trabajo con sueños se fundamente en el manejo de un dispositivo terapéutico que hace uso de la proyección total (aunque lo mejor es hablar de identificación) es porque el sueño no es sino el resultado de una proyección parcial.

A esta altura, se puede ultimar que para Perls la proyección implicada en el proceso de formación de los contenidos oníricos indefectiblemente constituía un mecanismo patológico. Y a pesar de que el primer Perls vislumbró la existencia de contenidos agradables en los sueños (deseos proyectados) él no les concedió la importancia debida quizás a que su interés estaba puesto en la neurosis y sus síntomas, uno de los cuales eran las pesadillas. Incluso, a la postre, Fritz terminó por rechazar la idea de que los sueños fueran un cumplimiento de deseos (Perls, 1968, 1970, 1976). Sin embargo, un aspecto que es importante matizar es que mientras los sueños agradables tienen la cualidad de ocurrir en el mundo exterior, en contraste, los sueños desagradables, es decir, las pesadillas, al contener siempre "proyecciones... [de] una parte no deseada de [la personalidad]" (Perls, 1947, p. 240), (es decir, son también proyecciones parciales) éstas impiden o disminuyen la posibilidad de su cumplimiento. Es decir, aunque las pesadillas también representan deseos proyectados, estos son por naturaleza de tipo negativo (p. ej., el deseo de venganza o castigo), lo cual obstaculiza su realización o expresión en el entorno ya que si esto ocurriera implicaría el castigo, sentimientos de vergüenza, culpa, etcétera. Por consiguiente, las pesadillas son "la interrupción de un deseo" (Perls, 1970, p. 60), son la frustración de una necesidad en la situación onírica. De ahí que Perls (1969a) subrayara que "en los sueños... vemos un intento por superar estas frustraciones. Probablemente sepas que la mayoría de los sueños son pesadillas. La pesadilla es un sueño en el que te frustras y luego intentas superar eso" (p. 126). Así, la pesadilla tiene la peculiaridad de encarnar una doble situación inacabada ya que debido a su naturaleza onírica emerge como una respuesta que intenta superar las frustraciones acaecidas en la vigilia y, también, porque durante el desarrollo de la trama de la pesadilla la necesidad insatisfecha se ve frustrada en sus contenidos y ocasiona que el soñante se despierte. Lo cual según Perls (1969a) explica su carácter repetitivo, "los sueños recurrentes... significa que una gestalt no se ha cerrado. Hay un problema que no se ha completado ni finalizado y, por lo tanto, no puede retroceder al fondo... muy a menudo estos sueños repetitivos son pesadillas" (p. 90). Todo esto parece confirmar que cuando Perls estaba hablando de sueños en realidad se estaba refiriendo a las pesadillas. Es decir, la teoría gestalt del sueño es una visión clínica o patológica sobre la etiología de las pesadillas. De ahí que haya calificado a la mayoría de los sueños como pesadillas, lo cual se puede observar en su modus operandi en las diferentes transcripciones de trabajo con sueños (Perls 1967, 1968, 1969a, 1970, 1976), en donde reiteradamente todos los sueños relatados, sin excepción alguna, son interpretados como hoyos en la personalidad, evitaciones, dificultades existenciales, etcétera. De manera que cualquier sueño por más anodino que parezca es interpretado como un mensaje existencial de las partes proyectadas de la personalidad o de los problemas de la existencia (p. ej. véase el sueño de Jean en Perls, 1969a). Empero, dicha perspectiva contrasta con los hallazgos en materia de epidemiologia de las pesadillas, ya que según se observa las pesadillas no son tan frecuentes como Perls suponía, ya que las estimaciones de prevalencia para éstas entre la población adulta en general, habitualmente, están dentro del rango del dos al cinco por ciento.

Otro problema con estas suposiciones radica en que no se limitan exclusivamente al plano teórico, sino que sirven de fundamento para una forma de terapia de lo onírico en la que la semántica de los sueños se reduce unilateralmente a una proyección. Sin embargo, esta tesis no sólo tiene injerencia en la hermenéutica de lo onírico sino también en la base lógica de la técnica de trabajo con sueños. Es por ello que se conmina al paciente a relatar el sueño en la primera persona del presente indicativo pues se supone que este uso del lenguaje lleva a la asimilación o identificación de lo proyectado (Perls 1969a, 1976). iPero el hecho de que el sueño se relate en primera persona y en pasado no se debe a que este sea una proyección sino más bien a que éste es el relato de un recuerdo, de una experiencia pasada! Todavía se puede agregar que relatar el sueño en tercera persona le da al soñante cierta distancia que le ayuda a apreciar sus acciones más claramente. En este mismo sentido, se puede señalar que si bien relatar el sueño en primera persona puede 
ser revelador ello no implica irreparablemente que el verdadero significado de los sueños sea una proyección. En este mismo orden de ideas se ubica la representación dramática del sueño mediante la cual se busca que el soñante se identifique y vivencie nuevamente las emociones experimentadas durante el sueño. Pero nuevamente, aquí el artefacto terapéutico de la dramatización se suscribe a la gramática de la proyección. En todo caso es posible aceptar que, efectivamente, lo que es terapéutico en la metodología gestalt del trabajo con sueños no es el modo en que se relata el sueño, ni la representación de la trama onírica, ni el dialogo entre las partes opuestas del sueño, sino el significado emocional que los grafos oníricos encuentran en la vida del soñante. Es decir, no existe una gramática ni mucho menos una semántica gestalt de lo onírico, lo que en realidad se trabaja mediante los sueños, como todo terapeuta gestalt sabe, es la situación real del soñante. Ya que solamente cuando los contenidos del sueño encuentran su referente en la vida del cliente, o mejor cuando la vida del soñante encuentra su significante onírico, es que el trabajo con sueños se torna efectivo. En última instancia, se trabaja no con los símbolos oníricos sino con el significado que la situación real tiene para el soñador, situación a la cual se supone que apuntan los sueños.

\section{Conclusión}

A lo largo de estas páginas se ha revisado la teoría perlsiana del sueño y se han señalado los problemas ligados a sus enunciados teoréticos, así como los errores que se han infringido a la hora de definir el sueño, y las funciones psicológicas y terapéuticas que se le confieren, en la terapia gestalt. También se examinaron las implicaciones que tales supuestos tienen sobre el fundamento lógico y en los objetivos que se persiguen mediante el trabajo con sueños. Si bien el leitmotiv del presente escrito ha sido presentar una crítica a la teoría gestalt del sueño también se ha tenido como propósito hacer una exposición ordenada de la misma, tratando de responder a las tres cuestiones básicas sobre los sueños: cómo se forman, cuál es su función y cómo han de ser interpretados, es decir, cuál es su significado. Lo que, como ya se habrá notado, desde un análisis histórico del pensamiento de Perls no tiene una sola respuesta sino muchas, la mayoría de las veces discrepantes. En este sentido, se ha intentado mostrar la complejidad que la hipótesis perlsiana del sueño encierra, en contraposición, a la idea simplista que prolifera en los diferentes círculos psicoterapéuticos $\mathrm{y}$, lamentablemente, dentro del mismo ámbito de la terapia gestalt. Ya que este ejercicio crítico permite no sólo problematizar la noción que los profesionales de la gestalt tienen acerca de los sueños, sino también conduce a un replanteamiento de las creencias fundacionales de la terapia gestalt como, por ejemplo, de los conceptos de self, awareness y contacto, los cuales no sólo son insuficientes sino limitados para explicar la experiencia del sueño; y a desarrollar una línea de investigación alrededor del fenómeno onírico y del trabajo con sueños.

\section{Referencias}

Ceballos, D. (2016). Ello, sueños y agresión. Gaceta de Psiquiatría Universitaria, 12 (4), 380-390.

Perls, F. S. (1947). Ego, hunger \& aggression: A revision of Freud's theory $\&$ method. London: Allen \& Unwin.

Perls, F. S. (1948). Theory and technique of personality integration. American Journal of psychotherapy, 2(4), 565-586.

Perls, F. S. (1966). Gestalt therapy and human potentialities. En H. A. Otto (Ed.), Explorations in human potentialities (pp. 542-548). Springfield, Ill.: Charles C Thomas.

Perls, F. S. (1967). Dream theory and demonstration. Mill Valley, CA: Big Sur Recordings.

Perls, F. S. (1968). Neurosis, psychosis \& dreams. Big Sur, CA: Big Sur Recordings.

Perls, F. S (1969a). Gestalt therapy verbatim. Lafayette, CA: Real People Press.

Perls, F. S. (1969b). In and out the garbage pail. Lafayette, CA: Real People Press.

Perls, F. S. (1970). Four lectures. En J. Fagan \& I. L. Shepherd (Ed.), Gestalt therapy now: Theory, techniques, applications (pp. 14-38). Palo Alto, CA: Science \& Behavior Books.

Perls, F. S. (1976). The gestalt approach: And eye witness to therapy. New York: Bantam.

Perls, F. S. (2012a). Planned psychotherapy. En F. S. Perls, From Planned Psychotherapy to Gestalt Therapy: Essays and Lectures-1945 to 1965 Frederick Salomon Perls, M.D (pp. 15-40). Gouldsboro, ME: The Gestalt Journal Press (Trabajo original publicado en 1979)

Perls, F. S. (2012b). Psychiatry in a new key. En F. S. Perls, From Planned Psychotherapy to Gestalt Therapy: Essays and Lectures-1945 to 1965 Frederick Salomon Perls, M.D (pp. 85-127). Gouldsboro, ME: The Gestalt Journal Press (Trabajo original publicado en 1978)

Perls, F. S., Hefferline, R. F., \& Goodman, P. (1951). Gestalt therapy: Excitement and growth in human personality. New York: Julian Press 
David Ceballos: ORCID (https://orcid.org/0000-00032818-1512 | Correo electrónico: davidceballos@ live.com.mx

Recebido em 18.06.19

Primeira decisão editorial em 17.07.20

Aceito em 22.07.20 